\title{
Entre Adam Smith y la bomba de fuego: un concurso de la Real Sociedad Económica Segoviana de Amigos del País sobre la reforma fiscal de Lerena y Floridablanca (1786-1787)
}

\author{
José Manuel Valles Garrido \\ I.E.S. María Moliner. Segovia
}

Resumen

Es bien conocida la función que desempeñaron muchas de las sociedades económicas nacidas al calor de la campaña de Campomanes en 1776 como instrumentos propagandísticos de los centros de poder de la monarquía de Carlos III. La de Segovia es un ejemplo notable, como queda de manifiesto en lo relativo a las reforma de las rentas provinciales y a la nueva contribución de frutos civiles, que impulsaron Lerena y Floridablanca en 1785. El tercer tomo de sus Actas y memorias impresas (Segovia, 1787) fue dedicado integramente a difundir y justificar teóricamente dicha reforma. Aunque es patente el compromiso "gubernamental» de los autores de los escritos ahí publicados (Vicente Alcalá-Galiano, Vicente Matecón, Diego María Gallard), la sociedad segoviana presentó su propia intervención como un desinteresado impulso cívico, concretado en un amplio llamamiento a la «opinión pública», utilizando el consabido método de la convocatoria de premios para las memorias que mejor destacasen los perjuicios del antiguo sistema impositivo y la conveniencia del nuevo que se proponía. Dich a convocatoria dio como resultado el envío a la sociedad segoviana de una serie de escritos que, independientemente de su desigual mérito intelectual, pueden ser leídos como indicadores significativos de estados de opinión más o menos generalizados. El contenido de estos escritos constituye el objeto de este artículo.

Palabras clave

S. E. Segoviana. Reforma fiscal. V. Alcalá-Galiano. Rentas provinciales. A. Smith. CES.XVIII, núm. 16 (2006), págs. 217-242. 
Entre los últimos intentos de establecimiento de la Única Contribución y las reformas de 1785 se extienden para España unos años marcados por la primera guerra contra Inglaterra (1779-1783) en apoyo de los independentistas americanos ${ }^{1}$. Para subvenir al conflicto se recargaron los derechos de aduanas y algunos impuestos al consumo, aumentándose en un tercio las rentas provinciales y equivalentes desde 1780 hasta 1784, aumento que — como reconocería más tarde Floridablanca- costó mucho hacer efectivo, ya que los contribuyentes resistieron el repartimiento con todos los medios legales a su alcance. Pero sobre todo fue el recurso al crédito lo que permitió financiar la guerra, de modo que se creó, en 1780, deuda pública en forma de «vales reales». Hasta que acabó la guerra, e incluso después, continuaron las emisiones y los empréstitos negociados por el banquero Cabarrús.

Cabarrús, como complemento de su febril actividad financiera de esos años (empréstitos, vales reales, creación del Banco de San Carlos...), propuso el 22 de noviembre de 1783 una verdadera reforma de la Hacienda que pondría de nuevo sobre el tapete la vieja idea ensenadista de sustituir las rentas provinciales por un nuevo impuesto que gravaba la propiedad. El texto doctrinal básico de este proyecto de reforma de Cabarrús es el Memorial al rey sobre rentas y crédito público (22 de noviembre de 1783). El sistema que ahí diseñaba el financiero fue sometido a un proceso de discusión al más alto nivel, tras el cual quedó transformado por Floridablanca en todo un "paquete de medidas» que puede considerarse como una verdadera reforma fiscal muy matizada que, si no suponía una reversión radical del sistema — como se había presentado años atrás a «la Única» con todo su imponente aparato informativo y administrativo-, tampoco dejó de tener efectos importantes tanto sobre los rendimientos fiscales como, a la larga, sobre la evolución teórica de los diseños impositivos ulteriores que llevarían al modelo hacendístico liberal ya entrado el siglo siguiente ${ }^{2}$. La reforma fiscal que puso en marcha Floridablanca en 1785 se apoyaba en dos pilares

$1 \quad$ El 12 de marzo de 1779 — un mes justo antes del Tratado de Aranjuez, que selló la alianza entre Francia y España en este conflicto— se hizo presente al rey un informe sobre el estado en que se hallaba la asendereada Única Contribución, señalando como una de las mayores dificultades para su puesta en práctica las diferencias de estimación en los repartimientos entre las averiguaciones iniciadas en 1749 y la situación de 1770 .

2 En este sentido, el proyecto de Cabarrús y su redefinición ulterior por Floridablanca como «contribución de frutos civiles», así como la profunda reforma a que fueron sometidas las rentas provinciales (y en cuyo defensa participó muy activamente Vicente Alcalá-Galiano) constituyen una batería de medidas que, recogiendo ese planteamiento «posibilista» que tan bien había definido Arriquíbar, recibieron su respaldo teórico de diversos autores, y destacadamente de Adam Smith. 
fundamentales: la reforma y reducción de las rentas provinciales y la nueva contribución de los frutos civiles ${ }^{3}$.

Se pretendía aumentar las rentas del Estado, a base de disminuir las contribuciones, reformando las rentas provinciales. En esta orientación creo que pudo influir la representación que, a propuesta de Vicente Alcalá-Galiano ${ }^{4}$, hizo la Sociedad Económica de Segovia — de la que era secretario - el 15 de octubre de 1783 sobre la conveniencia de rebajar los derechos en la carne y el aceite a lo que contribuían los eclesiásticos, suprimiéndoles la refacción. Se trataba de una medida apoyada en el principio de aumentar el rendimiento de los tributos sobre los géneros de consumo, rebajándolos, aliviando a los vasallos más pobres y suprimiendo la injusta refacción de los eclesiásticos. Esta propuesta, apoyada en sólidos cálculos, fue muy bien acogida por el Gobierno, lo que le llevó a la Sociedad Económica Segoviana (siempre por iniciativa de su activo secretario Alcalá-Galiano) a ofrecerse al Gobierno como medio de difusión de los argumentos que apoyaban las nuevas medidas fiscales, convocando un premio para escritos que defendieran dichas medidas, así como dedicando todo un grueso tomo de sus Actas y memorias impresas a dicha defensa.

Las memorias que se publicaron en dicho tomo procedieron tanto del concurso convocado — la de Diego María Gallard— como del propio secretario

3 Archivo Histórico Nacional. Estado. Leg. 238. Aranjuez, 15 de mayo de 1784. Lo transcribe Gonzalo ANES, «La contribución de frutos civiles entre los proyectos de Reforma Tributaria en la España del siglo XVIII», Hacienda Pública Española, n. 27 (1974), págs. 21-45. El primer paso de la reforma lo constituyó el Real Decreto de 29 de junio de 1785 (reproducido en el tomo III de las Actas y memorias de la Sociedad Económica Segoviana de Amigos del País, Segovia, A. Espinosa, 1787; págs. 1-5). En él se daban las líneas maestras de la misma: de los tres sistemas de recaudación utilizados (arrendamientos, encabezamientos y administración directa) se decidió extender la administración directa y reformar los encabezamientos, con el fin de aliviar a los más pobres. Sobre esta base, se extendió la Instrucción provisional, de 21 septiembre de 1785 (reproducida en el tomo III citado de las Actas y memorias, págs. 5-23), en la que se estipulaba que se fijase, para cada provincia, la cantidad que debiera pagar cada pueblo anualmente por su encabezamiento. En los pueblos importantes en que se considerase conveniente establecer la administración directa, se aplicarían los Reglamentos con los tipos a exigir. La alcabala quedaba en ellos reducida. En cuanto a los frutos civiles, los citados Reglamentos hacían una distinción básica entre hacendados forasteros y hacendados residentes. Los primeros habían de contribuir con un $5 \%$ de sus rentas; los residentes, con un 2,5\%, atendiendo a que efectuaban consumos en el lugar. El nuevo método de encabezamientos, quedaba fijado por extenso en el Reglamento de 10 de mayo de 1786 (también reproducido en las Actas y memorias, t. III, págs. 25-80).

El desarrollo ulterior de la reforma emprendida supuso, sobre la marcha, una serie de «retoques» que, en algún caso, la matizaron y en algún otro la redujeron en su pretendida profundidad: por ejemplo, el 11 de junio de 1787 se liberó de los frutos civiles al estado eclesiástico.

4 Vicente Alcalá-Galiano (1757-1810) era artillero y profesor de matemáticas en el Real Colegio de Segovia. Desde la fundación de la Real Sociedad Económica de Amigos del País de Segovia, destacó como uno de sus más activos socios, desempeñando en ella el cargo de secretario durante los años a que se refiere este trabajo. A este personaje he dedicado mi tesis doctoral (UNED, 2002), de la que se ha publicado ya la parte que estudia su labor de divulgador científico: José Manuel Valdes Garrido, Un científico Amigo del País en la España de la Ilustración: Vicente Alcalá-Galiano (1757-1810), Novelda-Madrid, Fundación Jorge Juan, 2004 . 
de la Segoviana Vicente Alcalá-Galiano (que redactó un documentado trabajo con el que apoyaba la reforma fiscal de Floridablanca/Lerena). Como consecuencia, Galiano fue requerido por Lerena como colaborador en la Secretaría de Hacienda ${ }^{5}$, convirtiéndose a partir de ese momento en el principal experto hacendista de dicho Ministerio.

Las memorias de Gallard y Galiano son conocidas, gracias a su publicación por la Sociedad Económica Segoviana; pero no así el resto de las que se presentaron, que no fueron muchas ni de una gran calidad, aunque no dejan de tener interés. A exponer su contenido se dedica este trabajo.

El concurso de la Real Sociedad Económica Segoviana de Amigos del País sobre la reforma fiscal

El objetivo principal de la Sociedad Segoviana era — como el del resto de corporaciones análogas de la época- el fomento económico de la provincia, lo que implicaba en un primerísimo plano el fomento de las fábricas, de la industria textil. Y un medio inequívoco de animar la actividad fabril era, entre otros, tratar de disminuir los costes de producción; tanto los derivados del trabajo como los de la materia prima. $\mathrm{Y}$ ahí es precisamente donde entran en juego las medidas fiscales: luchar, por un lado, para evitar la extracción de lanas, y, por otro, intentar que los salarios pudieran mantenerse bajos, manteniendo baratos los consumos. Lo primero tocaba a la política arancelaria, y lo segundo a los impuestos indirectos.

La primera intervención de Vicente Alcalá-Galiano defendiendo medidas fiscales que la Sociedad Económica habría de proponer al Gobierno, se produjo en junio de 1783: seguramente animado por la reciente disposición ${ }^{6}$ que permitía la extracción de granos siempre que su precio no alcanzase ciertos valores fijados, propuso Galiano que se recargase la extracción de lanas para fomentar la de granos. Ante la aparición de un Real Decreto (2 de julio de1783) en el que se establecía un recargo a la extracción de lanas similar al propuesto por Galiano, la Sociedad Segoviana le instó a su activo secretario para que variase su anterior propuesta $\left(9\right.$ de julio ${ }^{7}$ ). Éste, en la siguiente sesión, comentó el reciente decreto de recargo

\footnotetext{
5 Alcalá-Galiano fue nombrado el 11 de noviembre de 1787 comisario de Guerra, pero el contenido de su encargo era, claramente, asesorar al ministro de Hacienda. La incorporación más formal al Ministerio, ya como oficial de la Secretaría del Despacho de Hacienda, se produjo con fecha de 29 de mayo de 1789.

6 Real Cédula de 22 de Febrero de 1783. AMS. Leg. 953-5.

7 Todas las referencias puntuales a las actividades de la Sociedad Económica de Segovia proceden de sus actas manuscritas, que se conservan en el Archivo Municipal de Segovia en cuatro tomos con las siguientes signaturas: SESAP: Actas-1 (1780-1787), Actas-2 (1787-1793), Actas-3 (1793-1800) y Actas-4 (1801-1805).
} 
y presentó una nueva propuesta acerca de los granos: esta vez se trataba no de estimular su extracción, sino de dificultar su introducción de fuera recargando el extranjero ${ }^{8}$. Sólo tres meses después de estas propuestas, en octubre de 1783 , Galiano redactaba una nueva solicitud de tipo fiscal que suponía ya una incursión mucho más seria (fundamentada en los correspondientes cálculos con datos reales de la administración de rentas de Segovia) en la compleja problemática de los impuestos indirectos al consumo: se trataba de una solicitud para que se rebajasen los millones y nuevos impuestos (carne y aceite) con el fin de desahogar a los pobres y fomentar las fábricas ${ }^{9}$. Estas peticiones, más o menos en la línea del reformismo oficial, fueron en parte incorporadas a la nueva normativa fiscal ${ }^{10} \mathrm{y}$, en lo que toca a la propia Sociedad Segoviana, la concesión en el verano de 1784 de la facultad de imponer medio real en arroba de lana que se extrajera, le dio unas posibilidades de acción muy grandes a través de la gestión directa de ese impuesto.

Sin embargo, no puede decirse que las propuestas de la Segoviana estuvieran dirigidas interesadamente a unirse a ninguna línea oficial establecida, ya que, en esos años, aún no existía un proyecto global claro de reforma fiscal: en efecto, hasta febrero de 1785 no ocupó Lerena el Ministerio de Hacienda y en junio de ese año es cuando fue emitido el decreto de «arreglo de Rentas Provinciales», con su correspondiente instrucción de septiembre.

La Sociedad Económica - y Vicente Alcalá-Galiano a su cabeza- se implicó en seguida en la campaña gubernamental para difundir y defender la nueva normativa de rentas provinciales. En primer lugar, acordando con Lerena el establecimiento de un premio de 1500 reales (a comienzos de 1786) para la memoria que mejor ilustrase los beneficios de los nuevos Reglamentos ${ }^{11}$. En febrero de 1787 Galiano y Mantecón ${ }^{12}$ presentan su memoria conjunta en la que

Acta 110, 16-Julio-1783.

9 Es el escrito que, con el título de Sobre los nuevos impuestos, fue publicado por la Sociedad Económica Segoviana en el tomo II de sus Actas y memorias impresas (Segovia, 1786, págs. 181-200). Puede verse una edición facsímil de este texto, junto con otros del mismo autor, en: Vicente AlCalá-Galiano, Sobre la economía política y los impuestos (ed. de José Manuel Valles Garrido), Segovia, Biblioteca de Ciencia y Artillería, 1992.

10 Especialmente, el Real Decreto de 2 de julio de 1783 y Circular de la Junta General de Comercio de 18 de julio de 1783. Y, en lo referente a la última solicitud —la de los nuevos impuestos_, el eco de la propuesta de Galiano no pudo haber sido más satisfactorio, ya que su espíritu quedó recogido perfectamente en los nuevos arreglos de rentas provinciales que constituirían la reforma de 1785.

11 El ofrecimiento de la Sociedad arranca de la sesión del 8-febrero-1786 (acta 218), en que Vicente Alcalá-Galiano encomió el nuevo sistema de rentas, sugiriendo a continuación la propuesta de un premio de 1.500 reales de vellón. La Sociedad acogió con entusiasmo la idea y, efectivamente, muy pocos días después (en la sesión del 20-febrero; acta 220), se leyó la Real Orden por la que el ministro autorizaba la publicación del mencionado premio sobre rentas, felicitando a la Sociedad por la iniciativa (Archivo General de Simancas. Secretaría y Superintendencia de Hacienda. Leg. 1.595. doc. 1.)

12 Vicente Mantecón y Arce era entonces oficial segundo de la Administración de Rentas de Segovia, socio de la Económica y colaborador de Alcalá-Galiano en sus primeros trabajos sobre impuestos (facilitán- 
se establece la doctrina «oficial» al respecto (Perjuicios del antiguo sistema de rentas provinciales; y utilidades y ventajas de el que se establece por los nuevos reglamentos ${ }^{13}$ ) y, un año después (y ya recibidas unas cuantas memorias aspirantes al premio convocado, y al cabo de casi cuatro meses de estar incorporado al equipo de Lerena), publica Alcalá-Galiano su Necesidad y justicia de los tributos... ${ }^{14}$, texto de calado mucho más teórico y general, empapado en la doctrina de Adam Smith, pero también dirigido esencialmente a fundamentar la reforma de las rentas provinciales y los frutos civiles. El resultado de todo ello fue, como hemos dicho, la promoción de Alcalá-Galiano como funcionario experto en el equipo del ministro Lerena.

Aunque el tema que estamos abordando aquí tiene múltiples aspectos de gran interés, quiero centrarme aquí solamente en el curioso concurso que celebró la Económica de Segovia en torno a la reforma fiscal, describiendo los diversos textos que fueron presentados, textos que, si no tienen en sí mismos una calidad relevante, puede ser útil darlos a conocer, tanto por tratarse de textos manuscritos prácticamente ignorados hasta ahora, como por constituir testimonios expresivos de opiniones diversas ante los problemas económicos de la época.

En la sesión de 8 de febrero de 1786, Galiano hizo ante la Sociedad una exposición en favor del nuevo sistema de rentas, subrayando los perjuicios que acarreaba el sistema antiguo; y, como colofón, propuso que se agradeciese al rey — por conducto del ministro de Hacienda — la atención prestada a la propuesta de la Segoviana sobre los nuevos impuestos, a la vez que se solicitase el poder «proponer al Público un premio de 1.500 rs.vn. para quien expusiese mas bien en una Memoria los referidos perjuicios del sistema antiguo y las utilidades que podían resultar del nuevo, con expresa prevención que se haría a los Autores de que corroborasen sus discursos con hechos tomados de lo que hubiesen observado en las Provincias, Partidos ó Pueblos donde residiesen, pues consideraba que con estos hechos y las razones que funda en el nuevo sistema recibirían nuevos esfuerzos, como podía inferirse de las memorias que tenía presentadas sobre Rentas» (sesión del 8 de febrero de 1786; acta 218). Se trataba, pues, de apoyar el nuevo sistema promoviendo un movimiento de opinión expresado, no por medio de argumentos teóricos o doctrinales, sino «con números» y datos locales.

dole, seguramente, la base empírica que necesitaba el secretario de la Económica). Por cierto que en agosto de ese mismo año de 1786 solicitó Mantecón aumento de sueldo, que le fue denegado (AGS. SSH. Leg. 1.595. doc. 7).

13 En Actas y memorias, III. Segovia, 1787, págs. 1-237.

14 «Sobre la necesidad y justicia de los tributos, fondos de donde deben sacarse, y medios de recaudarlos». En Actas y memorias, IV. Segovia, 1793, págs. 269-358. Puede verse edición facsímil en: Sobre la economía política, Segovia, BCA, 1992, ant. cit. 
Tres meses después (17 de mayo de 1786; acta 231) se recibía la primera memoria, cuyo autor resultó ser don Manuel Herimia Quintana, dependiente de rentas de Medina de Ríoseco y socio de la Económica de Lugo. Se presentaron dos memorias más y, en marzo de 1787, se hizo público el fallo, resultando ganadora la de Diego María Gallard, quien, además de obtener el premio, fue nombrado socio de mérito y recomendado a Floridablanca y a Lerena.

Al cabo de un mes, el ministro Lerena aprueba la actuación de la Sociedad Segoviana, ordenándola que imprima esta memoria «como las demás que sobre este particular se hayan presentado y que ulteriormente se presenten», incluyendo el Decreto, Instrucción y Reglamentos que contenían la normativa de la reforma.

El autor premiado cedió el dinero de su premio y dio 500 reales más para que la Sociedad propusiese otros dos premios: uno de ellos para una memoria que hiciera balance del reinado de Carlos III en lo referente a progreso económico, científico e industrial; y otro para otra que repetía en términos casi idénticos el que Gallard acababa de ganar: «¿Qué abusos reinan generalmente en la administración de todas las rentas pertenecientes al Real Patrimonio; o cuáles son los particulares de cualquiera de ellas considerada por si sola; y en uno y otro caso qué remedios son los más prontos y eficaces para evitarlos? Advirtiéndose que el que quisiere escribir sobre el $2 .^{\circ}$ problema podrá considerar todas las rentas en común ó una tan sola en particular». Con la repetición de la convocatoria (extendida ahora no sólo a la reforma, sino a todo el sistema de rentas), parece que se pretendía prolongar la manifestación de «la opinión pública», sin duda debido a la escasa participación en la primera convocatoria, insuficiente seguramente para llenar las expectativas del ministro, que debía pretender formar un amplio dossier para darlo al público.

Los premios fueron aprobados por el gobierno y publicados en la Gaceta en mayo de 1787. En julio de ese año se dio cuenta a la Sociedad de la recepción de un «Proyecto» de un tal Josef Colmenero, residente en el Puerto de Santa María, que no se ajustaba a las formalidades del premio ${ }^{15}$. Pocos días después, se comunicó la decisión de los socios encargados de ver las memorias, de hacer una mención honorífica de los autores de las dos memorias no premiadas en la

15 De este autor da Ernest LLuCH algunas noticias en Las Españas vencidas del siglo XVIII. Claroscuros de la Ilustración, Barcelona, Crítica, 1999, págs. 150-151: Se trata de un «militar y académico de la Real Sociedad Geográfica de Valladolid», es autor de varios proyectos que Lluch cita (tomando las referencias seguramente de la Bibliografía de autores españoles del siglo XVIII, de F. Aguilar Piñal; tomo V, Madrid, 1989, pág. 193) y que le sirven para caracterizarlo como ejemplo de influencia cameralista: Colmenero propugna — en aquellos años sesenta y setenta entre la impronta de Aranda y de Campomanes- la formación de sociedades económicas compuestas de oficiales del ejército. 
primera convocatoria. Una resultó ser de Joseph Pariente Ciércoles; la otra, la de Herimia y Quintana.

La respuesta pública a la convocatoria del premio, evidentemente, no había sido demasiado lucida. La memoria de Gallard era buena, pero las otras no tanto y, en todo caso, no cubrían las expectativas de fundamentar sólidamente la reforma fiscal. Galiano, por su parte, no se redujo en esta ocasión - como en tantas otras — a sus meras funciones de secretario. El año 1786 — que fue para él de una actividad societaria e intelectual verdaderamente febril — aún le dio lugar a redactar, aprovechando las vacaciones de Navidad, un amplio y documentado trabajo donde pretendía cubrir por completo los requerimientos de la pregunta que se había formulado para el premio de rentas. En julio de 1787 informa a la junta de la Sociedad de la existencia de dicha memoria,

la qual habia pensado presentar en Junta General y viendo que esta se retardaba mucho remitió su trabajo al Ministerio para obtener su aprobación: Que esta se había logrado, y que con este beneplácito la presentaba con más libertad a la Junta para que si era digna de su atención la mandase imprimir en el mismo tomo que la presentada [se refiere a la premiada, a la de Gallard]. La Junta en su vista acordó que para no detenerse más en la publicación de una ni otra procediese el Secretario a la impresión de la suya respecto a que la era muy lisongero este trabajo que redundaba a favor suyo, y venía a ser una apología de sus acuerdos.

El secretario de la Sociedad comenzaba a girar ya, de una forma clarísima, en la órbita del Ministerio de Hacienda, actuando con una resolución que rompía sin problemas la dinámica formal propia de la Sociedad ${ }^{16}$. Además, explotaba hábilmente su posición cada vez más a la sombra del poder para potenciar de paso sus propios intereses particulares: la memoria sobre rentas, que presentaba Galiano a la Sociedad, ya aprobada por el ministro (si no es que se la había encargado directamente Lerena), le convertía en el intérprete autorizado de la reforma fiscal, incorporando sus ideas al dossier oficial.

16 En realidad, se puede decir la propia Sociedad Segoviana que se había convertido en un canal de información gubernamental. Precisamente, uno de los concurrentes al premio de rentas convocado por la Sociedad, el autor de la memoria titulada «Abusos que reynan generalmente en la Administración de las principales Rentas» (Madrid, 26 de abril de 1788. AMS. SESAP, 12-263), alude con claridad a esa vinculación al gobierno: «Si la sabia y celosa Sociedad de Segovia, ya que se ha distinguido en ocupar gran parte del tiempo en asuntos de Ministerio, expusiese â este algunos de los Pensamtos. insinuados, si la parecen conformes, ¿no veriamos la Peninsula llena de felicidades en la presente epoca del insinuado Colvert Español?». Y otro de ellos, el subteniente don José Fontaner, envía su memoria junto con la petición de que la Sociedad interceda para que se le atienda con un destino lucido de comisario de guerra o similar (Puerto de Santa María, 27 de agosto de 1787. AMS. SESAP. 12-263). 
Sin embargo, no todo era «interés oficial» en este asunto. También la Sociedad Económica Segoviana (y en ello Galiano era también su intérprete autorizado) tenía especial empeño en dejar patente ante la «opinión pública» los beneficios y la oportunidad de su famosa propuesta de rebaja de los millones y supresión de la refacción eclesiástica. Y es que dichos acuerdos sobre los millones (aunque habían recibido el espaldarazo oficial) debieron provocar bastantes críticas ${ }^{17}$, lo que sin duda no dejaría de potenciar también la identificación de la Sociedad Segoviana con la política fiscal.

El premio sobre rentas se mantuvo un par de años más, pero en la sesión de 3 de octubre de 1787 se daba cuenta ya a la Sociedad de estar concluida la impresión del tomo III de Actas y memorias, que contenía lo que quedaría como dossier oficial en apoyo de la reforma de Lerena: los textos legislativos más las memorias de Gallard y de Alcalá-Galiano/Matecón. El escaso impulso de participación inicial quedó en las nuevas convocatorias del premio bastante más desvaído, presentándose al cabo tres memorias, de las que ninguna alcanzó el galardón, destacando solamente una titulada Abusos que reinan generalmente... ${ }^{18}$ (las otras dos estaban firmadas por «Isidoro de Andrade Guzmán»; y José Fortaner, del Puerto de Santa María). Con carta de 15 de abril de 1788 se envió una desde la ciudad italiana de Faenza; otra llegó en julio de 1789. En diciembre de 1789, Momediano y Galiano dictaminan negativamente sobre 3 memorias presentadas.

El contenido de todas estas memorias es muy desigual: en general, bastante farragoso y repetitivo. Comentaremos solamente los aspectos más destacados.

— Joseph Pariente Ciércoles ${ }^{19}$ : Memoria sobre Rentas, presentada a la Sociedad para alcanzar los premios ofrecidos en el año de 1786 y dados en 1787. (4 hojas + 68 págs. + tabla de contenidos).

Comienza presentando los principales componentes de las rentas provinciales. Después, una introducción bastante desorganizada. Luego, los perjuicios: uno de ellos, el no entrar íntegro el producto en las arcas del Estado. La visión más o

17 Se dice en el acuerdo de la Sociedad que estamos citando que Galiano emprende la redacción de su memoria, no sólo para apoyar la reforma de Lerena, sino también, más específicamente, «para que constase los sólidos fundamentos del acuerdo de este Real Cuerpo y quedasen en tierra las siniestras interpretaciones que habían algunos llegado a dar a aquella resolucion» (Actas ms. II, 18-7-1787. n. ${ }^{\circ} 280$ ).

18 Sobre esta memoria conserva el Archivo Municipal de Segovia un análisis y valoración por parte de Vicente Alcalá Galiano, al que me referiré a continuación.

19 De Josef Pariente Ciércoles existe en el Archivo de la Sociedad Matritense una memoria presentada en octubre de 1786 a una convocatoria acerca de los «perjuicios resultantes a la labranza y cría animales de las fiestas de los toros». También en el Archivo de la Sociedad Aragonesa (Actas. Año 1781. Acta de 1-junio1781, ff. 78-88) puede verse una carta de Josef Pariente (fechada en Gijón a 4 de mayo de 1781) relativa a la introducción de la patata en Aragón. 
menos interrelacionada de los sectores productivos en este autor tiene como foco principal la población ocupada; el fomento de las manufacturas es de importancia primordial, sobre todo porque supone el mantenimiento de una población abundante y activa. En cuanto a España, considera que la expulsión de los moriscos supuso la consumación de la decadencia de los oficios, de las fábricas y, por consiguiente, de la introducción sin límite de géneros extranjeros. Cita a Damián de Olivares, a Moncada, a Fernández de Navarrete, a Uztáriz y al «autor de los tratados de los intereses de Inglaterra mal entendidos» ${ }^{20}$. También a Galiani, en relación con la insuficiencia de la agricultura sola para mantener una población; de donde deduce la necesidad de fomentar a la vez agricultura, manufacturas y comercio. Contra las contribuciones sobre los consumos argumenta que fomentan la ociosidad y favorecen la introducción de manufacturas extranjeras. Y considera un gran error por parte de los labradores el labrar con mulas, y no con bueyes.

Entre los beneficios del nuevo sistema menciona la mayor uniformidad en la recaudación que resultará, así como la posibilidad de crear montes de piedad al descargar las manufacturas con el abaratamiento de los consumos y, por tanto, de los jornales. En relación a los montes de piedad y pósitos de granos, cita a Cevallos, santo Tomás, Juan de Castro Gil González, Álvarez de Osorio, y el barón de Bielfeld. En realidad, el autor habla en esta parte, más que de los beneficios del nuevo sistema, de ciertas medidas que sugiere: entre ellas, además de los montes o pósitos, la creación de una Junta Popular de Agricultura e Industria en cada pueblo, que dé trabajo a todos, elimine la ociosidad y evite los errores de los oficios, todo ello bajo los auspicios de la Sociedad Económica. Esta Junta estaría presidida por el párroco y compuesta de personas acomodadas e instruidas de los estados noble y eclesiástico.

Una de las medidas en las que más insiste Pariente es en la introducción del ganado vacuno y el destierro del mular, que apoya en autores agrarios como Herrera, Deza, Gutiérrez y Valcárcel, proponiendo que se premie con honores a quienes vayan utilizando el vacuno; de lo que se espera la producción de grandes excedentes de grano que podrán incluso exportarse a América.

Finalmente, pone también grandes esperanzas en el empleo de los propios de los pueblos para dotar escuelas de primeras letras en las que, precisamente, había de emplearse el método de san Ildefonso. Se mencionan otros «medios» más, siempre insistiendo en que el nuevo sistema descargará de tributos a los pueblos, con lo que éstos podrán impulsar con más desahogo actividades productivas, así como ocupar más y mejor a la población.

20 Debe tratarse de: [Dubos, Jean Baptiste (1670-1742)], Les interets de l'Angleterre mal-entendus dans la guerre presente, Ámsterdam, Chez J.L. de Lorme, 1704. 
- Manuel Herimia Quintana: Memoria de los perjuicios que resultaban a la Causa pública por el methodo antiguo de administrar las rentas provinciales, y de los beneficios que puede producirle la práctica del nuevo Reglamento. (19 hs.)

Herimia, que se identifica como dependiente de Rentas en Medina de Ríoseco, así como miembro de la Sociedad Económica de Amigos del País de Lugo, comienza su memoria haciendo un apretado resumen del sistema de rentas hasta 1750 (fecha de la extensión de la Administración a las 21 provincias, con el mantenimiento del valor de los encabezamientos en ese momento). La gran desigualdad existente motivó, según Herimia, el que Fernando VI pusiese en marcha el vasto proceso de estimación de la riqueza que daría lugar al Catastro; si bien sería Carlos III el monarca destinado a desplegar el más completo programa de reformas económicas, administrativas y culturales. Tras las dificultades de los años de guerra 1779-1782, se abren de nuevo en los años 1784 y 1785 horizontes de progreso: la promoción de la industria y los oficios siguió con la exención de alcabalas, la honra de oficios, etc. Menciona también la creación de 44 sociedades económicas en los últimos 10 años, como otro índice de progreso.

La Administración de Rentas tuvo desde 1750 para este autor efectos muy positivos, determinando entre 1752 y 1757 el ahorro de 35 millones de reales. Los nuevos Reglamentos vendrán, pues, a completar y perfeccionar esta obra. Su cumplimiento, previene, podrá disgustar a los ricos, que contribuirán más; sin embargo, en compensación, los bienes manufacturados (al disminuir los consumos) les saldrán más baratos, y ellos consumen más que nadie. A la vez, el 10\% sobre las manufacturas extranjeras impulsará a la industria nacional.

En conjunto, la memoria es demasiado general y no se detiene ni en cuestiones teóricas ni en detalles técnicos.

-Diego M. ${ }^{a}$ GalLARD: Ventajas políticas de España por los nuevos Reglamentos de rentas provinciales, tanto en la menor, mas uniforme y equitativa contribucion del Vasallo, como por el fomento que resulta á la Agricultura, al Comercio, y las Artes. [Publicada en el tomo III (1787) de Actas y memorias de la Sociedad Económica de Segovia. Págs. 81-363].

La de Gallard es una memoria extensa (280 páginas), en la que se despliega una amplia erudición. Comienza en el prólogo oponiendo al viejo «espíritu de conquista» el moderno «espíritu de comercio», a la vez que destacando la importancia esencial que tiene la buena gestión de la Hacienda, tanto por lo que respecta a los crecientes gastos del Estado, como al comercio y a la economía de los vasallos. Ya en esos primeros párrafos puntualiza que la consideración de las rentas provinciales como el mayor obstáculo al comercio había que entenderla 
«por su excesiva qüota y dispendiosa recaudacion mas bien que por lo esencial de estos tributos» (pág. 86).

Ajustándose a las dos cuestiones propuestas en el premio, Gallard distribuye su memoria en dos partes: una, dedicada a los vicios del antiguo sistema de rentas provinciales; y otra, sobre los remedios que aporta el nuevo.

Algunas pinceladas de filosofía social y política abren, como suele suceder en escritos de este tipo, la primera parte. «La fortuna, la libertad, los bienes, la vida misma de los Ciudadanos, todo procede del Estado en la Sociedad...» (pág. 93). De ahí se deriva la obligación de los hombres de mantener el «Cuerpo Político» que han formado «por un pacto tácito ó expreso» (pág. 93). Establece una diferencia principal entre la economía de un gobierno y la de un buen padre de familia: «este proporciona los gastos á sus rentas, aquel ajusta sus rentas á las necesidades» (pág. 98). Considera la necesidad de reforma del sistema de Hacienda español como expresada por gran número de autores (del siglo XVII especialmente); pero sólo emprendida desde la llegada de Felipe V.

Tras exponer el origen de las rentas provinciales, pasa a considerar los defectos que se les atribuyen. El primero de ellos sería su diversidad, de donde se podría deducir la conveniencia de una contribución única. Sin embargo, su establecimiento sería tan complejo que no resulta apropiado «para remediar un mal urgente» (pág. 125). Por el contrario, la diversidad de tributos es la norma en todas las naciones; $y$, por otra parte, los impuestos sobre los consumos tienen la ventaja de que el contribuyente no siente su exacción, al pagarla «voluntariamente» en el precio de lo que compra. Aduce en apoyo de esto último la autoridad de Grocio, Hobbes, Puffendorf y Montesquieu (atribuyendo a éste el juicio de que los consumos «son los más propios para las Monarquías» (pág. 126)). Finalmente, considera que es indiferente que las rentas de un Estado procedan de uno o varios ramos, siempre que cumplan las tres condiciones siguientes: primera, que el total de contribuciones sea suficiente para cubrir las necesidades del Estado; segunda, que los individuos contribuyan con el máximo de igualdad y proporción a sus fuerzas posible; y tercera, que no perjudiquen estas contribuciones al progreso de la agricultura, industria y comercio. Dándose estas condiciones, será preferible mantener o retocar los viejos sistemas, ya asentados, que cambiarlos por otros nuevos por más justos que sean.

Otro defecto de las rentas provinciales sería el encarecer y reducir el consumo y el comercio. Sin embargo, responde Gallard, Holanda e Inglaterra tienen mucho más gravados sus consumos; por lo que más bien es la debilidad económica la que hace que la incidencia fiscal sea menos soportable.

El defecto, pues, de las rentas provinciales no estará en ellas mismas, sino, como ha dicho al principio, en el modo de recaudarse. En primer lugar, es negativo 
el hecho de que la cuota de estos tributos recaía antes sobre una población próspera y abundante — la supuesta del siglo XVI— que luego ha disminuido mucho.

Además, en los siglos anteriores, fueron recaudadas principalmente por el sistema de arriendos y encabezamientos. El establecimiento desde 1749 del sistema de Administración ha hecho agravarse uno de los principales perjuicios del sistema: el excesivo número de empleados, que consumen una buena proporción del producto de las contribuciones. Los ingleses también ocupan a gran número de personas, pues tienen todas sus rentas en administración; pero ello se debe, según Gallard, a su sistema parlamentario, que le obliga al ministro a mantener amplios apoyos en la Cámara. En España, el rey puede actuar con plena libertad, sin requerir aprobación parlamentaria alguna, por lo que no debería ser problema reducir el número de dependientes.

Otros problemas son los malos modos de los guardas y a la falta de efectividad de los resguardos que vigilan el contrabando, así como la desigualdad e injusticia en las cobranzas. «El pobre debe contribuir como pobre, el rico como rico, y todos segun sus facultades» (pág. 161), lo que refuerza Gallard con el argumento de que el rico tiene mayor interés en la defensa del Estado por los mayores beneficios que de ella disfruta en su persona y en sus bienes.

Además, la reforma de la Hacienda es necesaria para atender las crecientes cargas del Estado. El incremento de la presión fiscal puede ser peligroso; y el recurso a la deuda no hace más que aumentar a la larga los empeños del Erario; además, aumenta la dependencia del extranjero y el número de ociosos rentistas.

En la segunda parte, lo primero que apunta Gallard no es en realidad una «ventaja» sino una «precondición» para el éxito del sistema: la necesidad de formar un catastro (págs. 176-177). Esa necesidad de información estadística será uno de los aspectos a los que Gallard — hombre de libros y papeles, además de viajero cosmopolita — se muestra más sensible. En realidad, esta cuestión acabará centrando su dedicación profesional, impulsando la edición del Correo Mercantil y otras publicaciones económicas, así como gestionando ese gran productor de estadísticas que pretendía formar Lerena con su «Oficina de la Balanza del Comercio». Gallard conoce la diferencia entre lo poco que se ha hecho en España en este aspecto, y la situación de otros países, sobre todo Inglaterra (p. 179). Cita literalmente las instrucciones dadas a los intendentes para la elaboración del correspondiente catastro — paralelo a la obtención de los datos generales de población que constituirían el llamado Censo de Floridablanca-, pero expresa su opinión de que las noticias obtenidas han de ser sintéticas y claras.

Se han de reformar los encabezamientos con arreglo al catastro, ya que aquéllos fueron hechos en condiciones muy diversas en unos pueblos y otros, 
además de que, en general, han quedado muy desfasados. Gallard se manifiesta más partidario de la Administración que del Encabezamiento, siempre que sea posible, ya que aquélla permite atender mejor la situación real de los vasallos.

Uno de los argumentos más sólidos en favor de los nuevos reglamentos era, indudablemente, la rebaja sustancial que suponían para el contribuyente, sin disminuir por ello los ingresos del Erario. Ello se explica tanto por la mejor administración como por el efecto reanimador de la actividad económica que tendrá la reforma ${ }^{21}$, que hará que aumente la población: aumento tanto físico (o numérico) como «político» (o sea, aumento de población «útil» u ocupada) (p. 269) 22. La baratura de comestibles que propician los nuevos Reglamentos la considera Gallard, además, útil para atraer a los extranjeros industriosos.

¿Y no habría que gravar también las ganancias de los que ejercen artes liberales y de los sueldos de los empleados, igual que se carga a los hacendados? Gallard responde a esto con la pirueta de que imponiendo sobre los frutos de la tierra, el hacendado recarga a su vez el precio de esos frutos, con lo que distribuye esa carga entre los demás consumidores. Y, ante la posibilidad de ser tildado de fisiócrata, se apresura a dejar claro que no cree que todos los derechos del estado se deberían imponer sobre los frutos de la tierra. Por otra parte, imponer un derecho a los empleados supondría «una especie de capitacion ó tributo personal, el qual no es propio (segun nos dice un Autor bien conocido) sinó para las grandes y extraordinarias urgencias» (pág. 282) ${ }^{23}$.

En cuanto a las exenciones eclesiásticas, que los nuevos reglamentos respetan, Gallard se confiesa partidario decidido de mantenerlas. Otra cosa ocurre con la obligación que dichos eclesiásticos han tenido (ya en el antiguo sistema) de contribuir como los demás vasallos en los consumos.

Los Reglamentos nuevos, al animar el consumo, favorecen también la agricultura y, al abaratarse los consumos y aumentar su demanda, el agricultor ten-

${ }^{21} \quad$ Este será un punto especialmente polémico, ya que el desconocido autor de la memoria Abusos que reynan generalmente en la Administración... (concurrente posterior al premio de rentas de la Sociedad) lo criticará con sorna, siendo contestado contundentemente por Alcalá-Galiano. Véase esta cuestión más adelante, donde analizamos la mencionada memoria y su juicio crítico por Galiano.

22 El poblacionismo de Gallard se manifiesta aquí en términos bien claros: «Como la verdadera fuerza del Estado consiste en el mayor número de hombres, los Legisladores mas sábios han hecho en todos tiempos leyes animando al Matrimonio. (...). Sin embargo, en la actualidad dificulto que séan suficientes todos estos favores, para hacer multiplicar los Matrimonios. Necesítase tal vez otra Ley Papia contra los solteros libertinos, que defráudan maliciosamente este tributo de la naturaleza y esta obligacion del Vasallo» (pág. 27ln).

23 Ese autor es mencionado por Gallard a pie de página: «Mr. de Forbonnais. Considerations sur les finances. Tom. 4. p. 110» (pág. 282n.). Lo cita más adelante (págs. 324-325) como Recherches sur les finances. Tom. 3. Se trata, en ambos casos, de la misma obra: François Véron Duverger de Forbonnais, Recherches et considérations sur les finances de France depuis l'année 1595 jusqu'à l'année 1721, Liège, 1758, 6 vols. 
drá motivos para aumentar sus labranzas, sus ingresos, y, en consecuencia, sus propios consumos, fomentándose así los diversos oficios ${ }^{24}$.

Y, como no podía ser menos, la reforma favorece también directamente a la industria y oficios, al mantener bajos los precios de los mantenimientos y de las materias primas (pág. 314). La dominación española de extensos territorios ultramarinos hace aún más necesario el fomento de la industria, que Gallard considera brillantemente impulsado por la dinastía reinante.

Finalmente, hace Gallard la apología de la libertad de extracción de materias primas, como forma de estimular la producción interna de las mismas, poniendo el clásico ejemplo del Reglamento inglés de 1689 sobre extracción de granos. En cuanto al comercio en general, afirma Gallard que los nuevos reglamentos favorecen tanto el interior como el exterior. Y, en lo que se refiere a la tan denostada introducción de manufacturas extranjeras, Gallard defiende que se les pongan obstáculos arancelarios, como hacen otras naciones en defensa de sus intereses, si bien haciéndolo con «grande tiento» (pág. 342) y, en general, recargando los de lujo y descargando los de necesidad de que se carezca en España.

Los últimos apartados de la memoria tratan de los intercambios exteriores: el arreglo de las aduanas, que considera imprescindible para conocer la llamada «balanza del Comercio». Considera de gran importancia la reducción de las aduanas y el arreglo de los aranceles (simplificándolos y tipificándolos según los diversos productos), arreglos ambos que convergen en un mismo objetivo: llevar a cabo las labores estadísticas necesarias para poder emprender una auténtica «política comercial» basada en datos reales precisos, a la vez que orientar ventajosamente a los comerciantes ${ }^{25}$.

Gallard, como vemos, más que defender los nuevos Reglamentos, realiza toda una defensa general de la política económica oficial en muy diversos aspectos. Por ejemplo, exalta el beneficioso papel que, a su juicio, desempeña el Banco Nacional, haciendo circular por todo el reino el dinero.

Gallard maneja una aceptable información estadística, sobre España y sobre otros países, así como una abundante erudición antigua y moderna sobre tributos.

24 Incluso Gallard —en el colmo del entusiasmo por el efecto multiplicador de los nuevos reglamentos- considera que «la menor contribucion de las Aldeas podrá hacer que se establézcan allí las Fábricas, y de este modo se anima la Agricultura al paso que se foméntan las Artes» (pág. 309n).

25 Ya hemos comentado que, precisamente, uno de los resultados de su participación en el concurso de la Sociedad Segoviana fue para Gallard su promoción a importantes labores de «traducción y documentación» al servicio del ministerio de Hacienda: colaboración en la Colección alfabética de los aranceles de Francia (1789) y en la de los Aranceles de la Gran Bretaña (1792), traducción de la correspondencia de Cabarrús, edición del Correo Mercantil y gestor del primer intento de Oficina de la Balanza del Comercio, puesta al día de la recopilación legislativa de Hacienda de Ripia, etc. Sin olvidar que, más adelante, tendría ocasión también de enfrentarse a los problemas concretos de la gestión industrial con la dirección de la Real Fábrica de Algodón de Ávila, donde llevó a cabo interesantes experiencias de gestión. 
Conoce bien la realidad económica europea, citando muchas veces el caso inglés. En este último aspecto, y dejando aparte los consabidos escritores económicos españoles (Moncada, Mata, Osorio, Zavala, Loynaz, Uztáriz y Ward...), destacan entre los franceses Montesquieu, Melon, Forbonnais, y, entre los ingleses, Hume, Withworth ${ }^{26}$ y Wyndham Weaves.

La buena acogida que tuvo esta memoria por parte de la Sociedad Económica de Segovia y por parte del Gobierno le valieron a Gallard el sucesivo encargo de comisiones y empleos por los ministerios de Hacienda y Estado ${ }^{27}$.

-Abusos que reynan generalmente en la Administración de las principales Rentas del Real Patrimonio y explicación de varios medios prontos, y eficaces para evitarlos. Madrid, 26 de abril de 1788.

Fue la memoria considerada mejor de las de la segunda convocatoria. Ya había sido realizada la impresión de las de Gallard y Galiano como tomo III de las Memorias de la Sociedad en 1787, por lo que no se imprimió ésta. Sin embargo, se conserva entre los papeles de la Sociedad un amplio informe de Vicente Alcalá-Galiano sobre ella.

El autor, cuya identidad desconozco, confiesa desde el comienzo que se apoyará en aquellas memorias del tomo III para elaborar la suya y, efectivamente, cita con profusión tanto la de Gallard como la de Galiano y Matecón, aunque en múltiples aspectos critica su contenido.

En lo referente a los abusos del viejo sistema, insiste especialmente en sus problemas prácticos: por ejemplo, la falta de cumplimiento de las innumerables instrucciones por parte de los individuos de los ayuntamientos de los pueblos, gente poco instruída y poco dispuesta a buscar la normativa anterior que se cita en una orden. $\mathrm{O}$ la falta de cobro de las contribuciones a que están sujetos los eclesiásticos, o del $10 \%$ de los géneros extranjeros.

Más interés y extensión tiene la segunda parte, dedicada a los medios para evitar los abusos. El autor comienza sintetizando eclécticamente, a partir de las memorias de Gallard y de Galiano hasta 24 máximas sobre tributos y 25 requisitos que deberían cumplir los tributos. Hace después un sucinto recorrido histórico por los diversos tipos de tributos entre pueblos antiguos y modernos,

26 Charles Whiтworth (1714?-1778) fue editor de Davenant y autor de State of the trade of Great Britain from the year 1697 (London, 2 vols.) y de Commerce de la Grande Bretagne et tableaux de ses importations et de ses exportations jusqu'à la fin de 1773 (Paris, 1777, LX-170 págs.). En cuanto al autor citado a continuación, se trata en realidad del cónsul inglés en Sevilla y Cádiz, Wyndham BEAWEs, cuya Lex Mercatoria Rediviva: or The Merchant's Directory, Londres, 1752, fue reeditada muchas veces (existe una reimpresión moderna de la 4. ${ }^{a}$ edición londinense de 1783: Ann Arbor: UMI Books, 2001).

27 En AHN. Estado. Leg. 3197. n. ${ }^{\circ}$ 4, puede documentarse parte de la carrera de Gallard. 
desembocando en el viejo sistema de rentas español que se inició en el siglo XIV con el establecimiento de la alcabala. Aquí destaca el análisis que hace de los catastros catalán y aragonés, con abundantes referencias a la Miscelánea de Zavala, pero mostrando un conocimiento directo del asunto, lo que le permite resaltar el importante fraude que en la elaboración de dicho catastro se producía. Entre los catastros de Cataluña y de Aragón, considera más injusto al primero; pero ni uno ni otro le parecen adecuados como «equivalentes» para las rentas provinciales. Para encontrar tales «equivalentes» propone 10 posibilidades (cargar la harina, siguiendo a Loynaz; o bien gravar la tierra; o los géneros extranjeros y de lujo; o las casas; o el tabaco y la sal; o los propios y arbitrios; o las mulas, coches y lacayos; o los censos; o el diezmo; o la nobleza) que no considera apropiadas.

Al considerar los nuevos reglamentos, así como las memorias de Gallard y Galiano, muestra un escepticismo y un espíritu crítico propios del individuo que conoce no sólo la teoría fiscal, sino su práctica. Duda que puedan reducirse significativamente los gastos de administración y resguardo (al contrario, supone que la plantificación de las nuevas administraciones los aumentarán ${ }^{28}$ ), por lo que, el esperado aumento en los rendimientos sólo podría provenir de un aumento de hecho en las contribuciones. Y plantea una de las cuestiones cruciales del sistema: ¿por qué han de pagar más sólo los castellanos?: «¿Son estos vasallos de peor condicion que los Aragoneses, Valenzianos, Catalanes, Mallorquines, Americanos \&a?».

Otro de los problemas de los nuevos reglamentos afectaba a la nueva contribución de frutos civiles que, considera atinadamente el autor, despertará la oposición y resistencia de los hacendados. Éstos, en su mayor parte nobles, han de gozar, en su opinión, de privilegio fiscal. Además, está el problema que señalaba Gallard de que el hacendado repercutirá sobre los pobres (al aumentar los precios) lo que paga de más en su contribución.

Tiene muy claro que es preciso «desterrar pronta y perpetuamente de España» lo que él llama «las malditas Rentas Provinciales», para lo cual ha de buscarse el adecuado equivalente. $\mathrm{Y}$ el autor lo encuentra en una diversa serie de «arbitrios»:

1. Sustituir rentas provinciales y catastros por un tributo sobre el chocolate (es decir, sobre el cacao, el azúcar y la canela), género que no toman los pobres.

$28 \mathrm{Si}$, de acuerdo con Gallard, es imprescindible realizar un Catastro, es indudable que su elaboración requerirá emplear mayor número de dependientes y que, al mismo tiempo, los pueblos tendrán la oportunidad de renovar o ampliar sus ocultaciones. 
2. Cargar 4 mrs. por cada uno de los 900 millones de árboles frutales que habría en las 22 provincias de Castilla. Tributo semejante al anterior, ya que considera que el pobre no consume fruta, y sí el rico.

3. Obtener una bula del papa para eximir de los ayunos y abstinencias, lo que tendría - aparte de positivos efectos espirituales— la virtud de promover la producción de carne, así como hacer contribuir a los navarros y vizcaínos.

4. Promover la riqueza de los pueblos mediante la construcción de canales de navegación y de riego, emitiendo vales reales para su financiación.

5. Una lotería.

6. «La presion de la Atmosfera, con un poco de Política, basta para mejorar notablemente la Agricultura, en España, y para que las fabricas experimenten mil utilidades». Con este curioso enunciado nos presenta el autor un arbitrio no muy común en España en aquellos años, aunque sí muy de la época: la «bomba de fuego» o máquina de vapor. La que se propone aquí es muy sencilla y se basa en modelos tomados de los libros de ingeniería hidráulica de Belidor (1737) y del abate Bossut (1771): ambos textos incluían descripciones clásicas de la bomba de fuego, que se estudiaban como teoría incluida en los cursos de matemáticas de muchas academias. La de Artillería de Segovia, por ejemplo, incluía esta descripción en el tomo IV del Curso matemático de Giannini (Valladolid, 1803) basándose en las obras de Belidor, Desaguliers y Bossut, que solían tomar como «modelo» el ya muy trasnochado de «la bomba a fuego construída en Fresne para sacar el agua de las minas de carbón de aquél país» ${ }^{29}$. Propone difundir este tipo de bombas por todo el territorio, principalmente para elevar el agua, como medio alternativo mucho más barato que la construcción de canales para el riego; incluso se detiene en explicar («en terminos que puedan comprenderlo aun los Labradores») los fundamentos físicos de dicho artefacto.

La formación matemática —así como la profesión militar— de este autor quedan bien patentes tanto en la importancia que da a este arbitrio científico, como en la forma articulada en que ofrece sus reflexiones.

Vicente Alcalá-Galiano, como hemos dicho más arriba, escribió un juicio crítico de esta memoria, a la que consideró la mejor de las presentadas, pero no merecedora del premio, aunque sí de alguna distinción. Este Juicio crítico se conserva manuscrito, en el Archivo Municipal de Segovia, entre las diferentes memorias que concurrieron a los premios de la Sociedad, y tiene un interés especial: fue «algo más» que un mero informe interno a la Económica de Segovia.

29 Pedro Giannini, Curso matemático para la enseñanza de los caballeros cadetes del Real Colegio Militar de Artillería, t. IV, Valladolid, Imprenta Real, 1803, pág. 284. 
Galiano, como es lógico, se centra en la segunda parte del escrito. Sobre las 24 máximas que enumera el autor sobre tributos, la última de ellas —que defiende el privilegio fiscal para la nobleza — la rechaza Galiano (y esa opinión contraria queda bien clara en su memoria con Matecón). Los 25 requisitos que debe cumplir un tributo le parecen de gran importancia a Galiano, y los copia íntegros. En cuanto al Catastro catalán, Galiano confiesa que no está al tanto de su práctica.

Sobre todo, Galiano no puede estar de acuerdo con la afirmación de que los nuevos reglamentos supondrán un aumento en las contribuciones. A este respecto, escribía el autor en el punto 140 de su memoria:

Uno de los que mas se han dedicado a defender la nueva planta [se refiere a Gallard, y a lo que escribe en la página 253 de su memoria], dice, que aun en el supuesto de que no resultase, en consecuencia de ella, mayor consumo de los primeros mantenimientos, no por eso se deberia tener desfalco alguno en el Erario. Sino padezco equivocacion, el espíritu del insinuado erudito Autor, es este: En los años anteriores se pagaba de tributo en las 22 Provincias, 8 mrs., por exemplo, por cada quartillo de vino que se vendia [\{añadido al margen\}: en vrd. de la nueva Planta se pagarà de tributo en las 22 Provincias $5 \mathrm{mrs}$. por exemplo por cada quartillo de vino que se venda; ] y sin embargo de que en cada año de los venideros, no se consuma mas vino en las 22 Provincias, que el qe. se consumía, ô consumio, en cada año de los anteriores, no por eso se debe temer que el Rey, perciba menos por el tributo del vino. Los que no son afectos a esta remocion de las rentas Provinciales ¿se conformaran con la opinion referida?

Galiano, en su Juicio crítico, no considera esta reflexión como una objeción a Gallard, sino que se da personalmente por aludido (pues él mismo ha defendido la misma opinión en su memoria con Matecón y la había sostenido y fundamentado en complejos cálculos algebraicos en lo referente al vino, así como cuantificando el valor de los derechos en las distintas especies antes y durante el primer año de vigencia de la nueva planta en Segovia), y responde del siguiente modo:

...el autor me parece se lisongea, y dá á entender haber hallado una proposicion evidentemente falsa en lo que tengo escrito sobre el particular. Yo diré que aun en el supuesto de que no resultasen por la rebaxa de derechos mayor consumo, no por eso deberia temerse desfalco alguno en el erario; pero añadí, que procederia esto de los muchos abusos que se remediaban con las nuevas providencias, y del menor contrabando, y lo acredité con lo que se habia verificado en Segovia, 
desde el establecimiento de la nueva planta. Este es el sentido obio, y genuino de la proposicion que combate, y mientras no acredite que es falsa la razon, y que tambien lo es el hecho en que se funda, subsistirá en toda su fuerza: si el autor supiera que en la arismetica de las aduanas, dos y dos muchas veces no hacen quatro, sino uno, no se le haria dificil la inteligencia de la proposicion que tanto ha extrañado.

En efecto, Galiano tenía ya muy estudiados y demostrados los abusos del antiguo sistema de rentas provinciales, como había puesto bien de manifiesto en su memoria Sobre los nuevos impuestos y en la que había escrito con Matecón. Sin embargo, en este caso, Galiano no se limita a reenviar al autor enjuiciado a sus comprobaciones empíricas sobre lo que ha ocurrido en Segovia; además, le obsequia con un desplante verbal que no es más que una reminiscencia de una lectura que ha hecho recientemente: la de Adam Smith. En efecto, la boutade sobre «la arismetica de las aduanas» la encontramos referida por Smith como un dicho del doctor Swift. Galiano la saca a colación, seguramente porque hacía poco que la había leído y le hizo gracia, a pesar de que la usa en un contexto que poco tiene que ver con las aduanas.

Más adelante, frente al escepticismo del desconocido autor sobre que pueda hacerse un buen catastro, Galiano muestra su confianza en el celo de los intendentes, e incluso en las neckerianas «Juntas Provinciales» que había propuesto en su escrito con Matecón; pero, sobre todo, confía en la mera revisión de los encabezamientos, tan desiguales y desfasados.

Sin embargo, incide el autor de la memoria enjuiciada sobre la novedad intolerable que supondrá el $5 \%$ de frutos civiles para los hacendados nobles. A lo que Galiano responde no con meras puntualizaciones, sino remontándose a los principios y dando entrada sucintamente a las ideas de Adam Smith ${ }^{30}$ : la riqueza consiste en el producto del trabajo, lo que en el caso de los hacendados quiere decir que de ese producto reciben éstos una parte (como propietarios) y el resto queda para salario (que no puede bajar del nivel de subsistencia) y anticipaciones del labrador. La renta que éste paga al propietario tiende a ser la más alta posible, debido a la posición preponderante de los hacendados. El 5\% de frutos civiles no afecta a los propietarios que cultivan sus haciendas, de modo que así se estimula la agricultura. A los que no las cultivan, Galiano justifica el recargo porque éstos por sí mismos no están dispuestos a bajar ni las rentas ni los precios (es decir, la fuente de su ganancia) y, siguiendo a Smith —y, en este

30 Ideas que, cuatro meses atrás, ya le habían servido de armazón esencial de su memoria Sobre la necesidad y justicia de los tributos. 
caso, citándole literal y nominalmente ${ }^{31}$ — , añade que la renta de tierras y suelos no le supone a quien la disfruta ningún trabajo ni atención ${ }^{32}$.

Repasa, finalmente, los arbitrios propuestos por el autor como equivalente de las rentas provinciales y considera que éstos «no llenan el Concepto que èl mismo se habìa propuesto, pues estàn sujetos à tanto ò mas abusos que las Rentas Provinciales», concluyendo que el autor, en su opinión, «irritado por los abusos que reynan en semejantes Rentas hà leido con preocupación [es decir, con desconfianza y excesivo espíritu crítico] las Memorias que se hallan en el tomo 3. ${ }^{\circ}$ de la Sociedad».

$\mathrm{Al}$ principio hemos dicho que interés de este Juicio crítico de Galiano sobrepasa un tanto el de mero dictamen interno de la Sociedad de Segovia. Está fechado en Madrid el 9 de Junio de 1788. Es, por tanto, cuatro meses posterior a la memoria de Galiano Sobre la necesidad y justicia de los tributos..., en la que utilizaba ampliamente a Adam Smith, y que — aunque escrita en marzo de 1788- sólo fue impresa cinco años después, en el tomo IV de Actas y memorias de la Sociedad de Segovia. Pues bien, el mencionado Juicio crítico... de Galiano —en el que, como hemos visto, también se citaba como autor básico a Smith - apareció impreso al año siguiente de ser escrito (es decir, en 1789) en el tomo VI de las Memorias políticas y económicas... de Eugenio Larruga, en su Memoria XXXIII, págs. 284-299. Dicha memoria trata sobre «Contribuciones reales y municipales de la provincia de Toledo», y en ella Larruga comienza exponiendo el intrincado amasijo de exacciones que recaían sobre todo sobre los pobres y la forma como la oligarquía municipal aprovecha en su beneficio el «sistema» (mediante la manipulación de los arbitrios, la refacción eclesiástica, etc.); se centra, sobre todo, en el arbitrio de la seda, para demostrar que - a pesar de ser aparentemente un género de lujo — recargaba en realidad a las 20.000 familias que vivían de esa industria.

Pues bien, Larruga concluye su análisis con un encomio de los nuevos reglamentos de rentas provinciales, que lograrán por fin imponer la equidad, haciendo que cese la oposición interesada de los ricos y la ignorancia del pueblo:

31 El pasaje (del libro V, cap. II, parte II, art. $^{\circ}$ I «Tributos sobre las rentas», de la Riqueza de las naciones) lo cita Galiano así: «La renta ordinaria de las tierras y de los suelos es una especie de renta que el Propietario disfruta la mayor parte del tiempo sin ningun trabajo ni atencion. Ninguna clase de industria se desanimarà por que parte de esta renta se tome para atender à los gastos del Estado. El producto anual de las tierras y del trabajo de la Sociedad, la riqueza real y la renta del Pueblo seràn las mismas antes y despues de semejante imposicion. Así qe. las rentas de los suelos, y la renta ordinaria de las tierras son las qe. pueden sufrir mejor qualquier suerte de impuesto particular».

32 En Sobre la necesidad y justicia de los tributos, Galiano había ido más allá aún achacando a los hacendados rentistas no sólo el consumir improductivamente sus rentas sino, incluso, dedicarlas a mantener gentes ociosas e inútiles que «influyen con su exemplo para que otros dexen de ser industriosos y aplicados» (pág. 302). 
Sobre este asunto ha llegado á mis manos un escrito del secretario de la sociedad de Segovia Don Vicente Alcalá Galiano, que por su juicioso modo de pensar, y porque toca, entre otros, un punto de grande importancia para desterrar la preocupacion, con que se oponen á todo establecimiento útil algunos, presumidos de políticos y economistas, pero enteramente ignorantes del estado actual económico de la Europa, y que jamás han meditado, ni tienen principios para conocer lo mas ó menos ventajoso á nuestra nacion, me ha parecido insertarlo aqui (pág. 282-283)

La cita muestra el ambiente de oposición con que se encontró la reforma de Lerena (no sólo en su realización efectiva, sino también —-significativamenteen su presentación, debate o argumentación en los circuitos que en aquella época ya formaban un embrión de «opinión pública». Además, el lenguaje de Larruga expresa muy bien ese «discurso oficial» que se estaba difundiendo desde el entorno ministerial para defender una reforma a la que se podría achacar cualquier cosa menos la falta de un soporte teórico bien trabado.

Sería muy interesante conocer la identidad del autor de la memoria enjuiciada por Galiano, pues pudiera tener alguna relevancia política. En cuanto a Larruga, archivero de la Junta de Comercio, no puede extrañar que defendiera con convicción la reforma fiscal de 1785, dada su vinculación a ese interesante proyecto de Oficina de Balanza de Comercio que impulsó Lerena apoyándose en un selecto grupo de profesionales incorporados en 1788 a tareas estadísticas y documentalistas muy especializadas. La herramienta principal de difusión de esta actitividad fue el Correo Mercantil que editaron, precisamente, Diego Gallard y Eugenio Larruga.

\section{— «alerianus Augustus»}

Esta memoria, cuyo autor parece eclesiástico por el lenguaje y el tono que emplea, es una soflama apocalíptica precisamente contra el nuevo sistema que se pretendía imponer. Hace referencia a altercados y motines en las ferias de Lugo y Santiago, lo que lleva a relacionar este escrito con la viva oposición que tuvo el nuevo Reglamento de rentas provinciales precisamente en aquellas tierras.

El tono del escrito es muy radical y primario. Este exaltado autor echa rápidamente las cuentas de las rentas del rey, que según él son bastante más crecidas de lo que suele decirse. A la hora de las propuestas, pretende, nada menos, que los 61 millones que, en total, viene ingresando la Hacienda Real, se repartan directamente entre las capitales (y éstas entre los pueblos respectivos) suprimiendo los empleos de rentas, e incluso los corregidores (que, para él, son 
«harto ladrones»), que serían sustituidos por alcaldes añales nombrados por los pueblos. La gran masa de empleados de rentas suprimidos se dedicarán a colonizar baldíos o a cubrir puestos públicos útiles en hospitales, etc. Sacando a censo los caudales de las órdenes mendicantes, se obtendría también un fondo para comprar las casas y aperos necesarios para el vasto proyecto colonizador, pretendiendo que se extienda a toda España el método de labranza de Galicia y Asturias. Asimismo, propone también la supresión del señorío; la aplicación del diezmo a usos benéficos y no a retribución de los eclesiásticos, que la tendrían del Estado; etc., etc. Una verdadera utopía popular que pone en un Estado todopoderoso el foco del nuevo orden.

— «Ad Regalem Oeconomicam Socitatem Segoviae privatim attinet de hac re difinita sententiam ferre censuram paregere». (22 pliegos)

El autor, cuya identidad desconocemos, se declara joven e inexperto, pero conocedor de algunas realidades fiscales que ha visto (menciona que ha estado en la toma de «Panzacola» ${ }^{33}$, ha conocido el contrabando que se efectúa en las Antillas, y ha servido bajo el coronel don Juan Cruz). Sitúa el origen de la decadencia española en el equivocado modo de aprovechar los recursos americanos.

Considera la enorme complejidad del sistema fiscal, aunque su propio análisis es, verdaderamente poco complejo y nada refinado. Entre los abusos antiguos señala las granjerías y refacciones de los eclesiásticos, las excesivas capellanías y obras pías que se han fundado, si bien quiere que se mantengan su dignidad y exenciones.

Frente a las manufacturas extranjeras de moda, ve dos alternativas: o superar a la industria extranjera, o "privarse de su censura, inventando un luxo nacional».

Y, finalmente, en el plano fiscal, propone (apoyándose en Zavala y Auñón) que toda la variedad de rentas vigentes sean subrogadas en una contribución personal a imitación del catastro catalán o aragonés, o del equivalente valenciano. Con ello, se ahorrarán multitud de empleados inútiles. Propone también que en todas las ciudades haya unas personas que, en secreto, asesoren al rey sobre los individuos capaces en ellas existentes. Cita elogiosamente los Discursos de Campomanes y las obras de Ulloa, Uztáriz, y la traducción de Francisco Javier de Goyeneche, marqués de Belzunce, sobre el comercio de Holanda.

Se refiere después a la renta de Tabacos, que demuestra conocer a fondo (sin duda gracias a sus empleos en América) y cuantifica. Trata el problema del

33 Es decir, Pensacola, el 10 de marzo de 1781. 
contrabando desde el punto de vista del excesivo número de empleados en el resguardo, mal pagados y, por tanto, nada escrupulosos.

—José Fontaner: Reflecciones que presenta Dn. José Fontaner Subteniente de el 2. ${ }^{\circ}$ Regimiento de Infantería Ligera de Cathaluña a la R.S.Ec. de Segovia, en las quales pretende el exponente manifestar a la nombrada Rl. Soc. los abusos que resultan generalmente en la Administración de las rentas del tabaco, y Millones de el Patrimonio Real, y quales son los particulares de estas dos consideradas cada una por sí sola (con arreglo al aviso que dio este año para el próximo de 88) manifestando el modo como podrán extinguirse los Contravandistas de la Monarquia (particularmente los de la renta del Tabaco)». Puerto de Santa María, 27-agosto-1787.

Es curioso que procediesen del Puerto de Santa María dos memorias: la de Joseph López Colmenero y ésta de Fortaner. Ambos eran militares. La de Fortaner era muy breve y tocaba dos puntos: la renta del tabaco (en la que había servido su autor como militar del resguard ${ }^{34}$ ) y la de millones. En lo referente a esta última, Fortaner defiende el sistema de encabezamiento asi como la reducción de empleados que éste hace posible, y la libertad del comercio interior. A pesar de lo poco trabajado de este escrito, el autor establece en un par de párrafos los «principios» impositivos que defiende: los tributos han de recaer sobre la renta de la tierra, ya que «como la tierra es manantial de las riquezas debe serlo tambien de los tributos». Aunque no habla de «producto neto», la influencia fisiocrática es visible, por ejemplo, en su concepción de la circulación del producto de los hacendados "para las empresas de Agricultura, Comercio é Industria».

Por otra parte, el principal interés de Fortaner al participar en el premio de la Sociedad era el conseguir un destino en Rentas. Se conservan algunas cartas que intercambió con Galiano en las que insistía en su deseo de ser «atendido» con un nombramiento de comisario de guerra o similar. Incluso en el Archivo de la Matritense existe una solicitud de este personaje en 1788 «para que S.M. le honre con el destino de administrador de rentas, por recomendación de la Sociedad $»^{35}$. El dato nos puede servir para corroborar esa «utilización» de las sociedades económicas por los militares para acceder a destinos en la adminis-

34 Dice Fortaner que estuvo un año a las órdenes del coronel don Juan Ortiz, persiguiendo contrabandistas en los reinos de Andalucía y Extremadura. Este Ortiz debe ser el que menciona Galiano en una de sus cartas a Saavedra sobre administración (Madrid, 12 de abril de 1798. Fondo Saavedra. Caja 26, n. ${ }^{\circ} 11$ ) como uno de los jefes militares de las Comisiones que se formaron para reprimir el contrabando, y de cuyos malos resultados se confiesa el mismo Galiano causante, al haber defendido su conveniencia.

En la memoria que comentamos, Fortaner se muestra contrario a la pura solución represiva, ya que es consciente de que el contrabando es una forma de vida que sostiene a muchas familias (no sólo a las de los contrabandistas, sino también a las de los funcionarios encargados de su vigilancia y administración).

35 Archivo de la Real Sociedad Económica Matritense. Leg. 83/7. 
tración civil; y no siempre había detrás de esa aspiración el esfuerzo intelectual y el impulso cívico de un Alcalá-Galiano.

—Domingo Muriel: Memoria sobre Rentas para el premio de 1788. Faenza, 15-abril-1788.

Esta Memoria trataba de responder a los dos asuntos propuestos por la Sociedad para el premio de 1788: uno, sobre el estado de las ciencias, artes y comercio en 1759, y modo de fomentarlo; y otro «sobre los abusos que reinan en la administración general o particular de la Real Hacienda» y medios de remediarlos. El autor es segoviano, y posiblemente ex jesuita, dedicado en Italia a la enseñanza. Toca diversos asuntos, que no podemos repasar aquí (defiende, por ejemplo, la educación pública). Piensa que el progreso, tanto económico como cultural, se podrá conseguir fomentando la concurrencia y la emulación, mediante «premios y apremios»: por ejemplo, para fomentar la agricultura (y, con ella, la población y la posibilidad de crecimiento económico) propone una ley para que los propietarios den todo el cultivo posible a sus fincas, o las pierdan siendo adjudicadas a otros con la misma condición. En cuanto a la Real Hacienda, desconoce que haya abusos en la Administración, aunque reconoce que hay atrasos. El remedio de los atrasos, para él, se reduce a fomentar la agricultura, completando ese agrarismo poblacionista con algunos otros arbitrios.

Finalmente, como hemos dicho más arriba, Vicente Alcalá-Galiano presentó también una memoria a la Sociedad, que se publicó en el tomo III de las Actas y memorias impresas de la Sociedad Económica de Segovia ${ }^{36}$, firmándola con el Oficial de Rentas de la provincia de Segovia, Vicente Mantecón y Arce. Su título: "Perjuicios del antiguo sistema de rentas provinciales y utilidades y ventajas de el que se establece por los nuevos Reglamentos» (Segovia, 17 de febrero de 1787). En ella establece la doctrina oficial en apoyo del nuevo sistema de rentas provinciales, apoyándola teóricamente con autores como el fisiócrata G.L. Schmid d'Avenstein (Principes de la Legislation Universelle. Ámsterdam, 1776), los autores españoles recogidos por Campomanes en los tomos del Apéndice a la Educación Popular; Zavala, Arriquíbar; y, especialmente J. Necker (De l'Administration des Finances de la France. Lausanne, 1784). El punto de contacto entre Schmid d'Avenstein, Necker y otro autor citado, el prusiano Hertzberg, será la insistencia en el establecimiento de unos cuerpos administrativos intermedios a escala provincial.

El análisis detenido de la memoria de Galiano nos llevaría más lejos; queda trazado en mi tesis doctoral y, en cualquier caso, daría pie ya a otro artículo.

$36 \quad$ Op. cit., Segovia, 1787, págs. 1-237. 
Nuestro objetivo en este trabajo se reducía, como dijimos al principio, estrictamente, a dar a conocer las diferentes respuestas a que dio lugar el concurso, poniendo así de manifiesto el posible interés de unos escritos ignorados que revelan puntos de vista coetáneos, y ciertamente sugerentes de pistas aún por explorar, acerca de los problemas fiscales de la España del siglo XVIII. 